\title{
Glutamatergic Modulation of Subcortical Motor and Limbic Circuits
}

\author{
DANIEL J. HEALY ${ }^{a}$ AND JAMES H. MEADOR-WOODRUFF \\ Mental Health Research Institute, Department of Psychiatry, University of Michigan, \\ Ann Arbor, Michigan 48109-0720, USA
}

The ventral striatum is a critical component of parallel circuits associated with motor and limbic functions, termed the corticostriatopallidothalamic circuit (CSPT). ${ }^{1}$ The interconnectivity of the regions comprising these circuits is believed to mediate the processing of sensory information that leads to the modulation of both motor and limbic behaviors. This well-defined circuitry allows for the neurochemical anatomical examination of functionally integrated regions. The striatum is one of the critical integrative areas in the CSPT because of the convergence of its glutamatergic and dopaminergic afferents, and the modulatory effects of its efferents. ${ }^{1}$

Corticostriatal glutamate projections synapse on mesostriatal dopaminergic projections, and modulate dopamine release in the dorsal and ventral striatum. ${ }^{2}$ Modulators of all four glutamate receptor subtypes-NMDA, AMPA, kainate, and metabotropic - affect dopamine release in dorsal and ventral striatum. We previously reported that systemic treatment with the NMDA receptor antagonist MK-801 alters $\mathrm{D}_{2}$ receptor mRNA in the ventral tegmental area (VTA) but not the substantia nigra, pars compacta $(\mathrm{SNc})$, or in the dorsal or ventral striatum. ${ }^{2}$ These data suggest that NMDA receptors exert a tonic effect on dopamine autoreceptor expression preferentially in limbic regions. We now present data from a follow-up experiment to determine the effects of other glutamate receptor modulators on dopamine receptor expression in caudate-putamen $(\mathrm{CPu})$, nucleus accumbens, core (core), and nucleus accumbens, shell (shell).

Sprague-Dawley male rates (225-275 g) were treated with seven daily injections of CNQX (an antagonist of both AMPA and kainate receptors), GYKI52466 (an AMPA receptor desensitization facilitator), riluzole (a glutamate release inhibitor), or DMSO (vehicle), and rats were sacrificed 24 hours after the last injection. ${ }^{3}$ Ten animals were treated per group. In situ histochemistry for preprodynorphin and preproenkephalin transcripts, and $\mathrm{D}_{1}$ and $\mathrm{D}_{2}$ receptor mRNAs was performed as previously described. ${ }^{2}$ Results are shown in FIGURE $1 . \mathrm{D}_{1}$ and opioid peptide precursor mRNA were not affected by any of the treatments, while $\mathrm{D}_{2}$ mRNA was significantly decreased by riluzole and GYKI52466 treatments.

Riluzole and GYKI52466 equally decreased the expression of $\mathrm{D}_{2}$ receptors in both dorsal and ventral striatal regions. This is in contrast to the effects of MK-801, ${ }^{2}$ and suggests that our previously reported results after NMDA receptor antagonist

${ }^{a}$ Corresponding author: Daniel J. Healy, M.D., Mental Health Research Institute, Dept. of Psychiatry, University of Michigan, 205 Zina Pitcher Place, Ann Arbor, MI 48109-0720. Voice: 734-936-2061; fax: 734-647-4130; drdan@umich.edu 

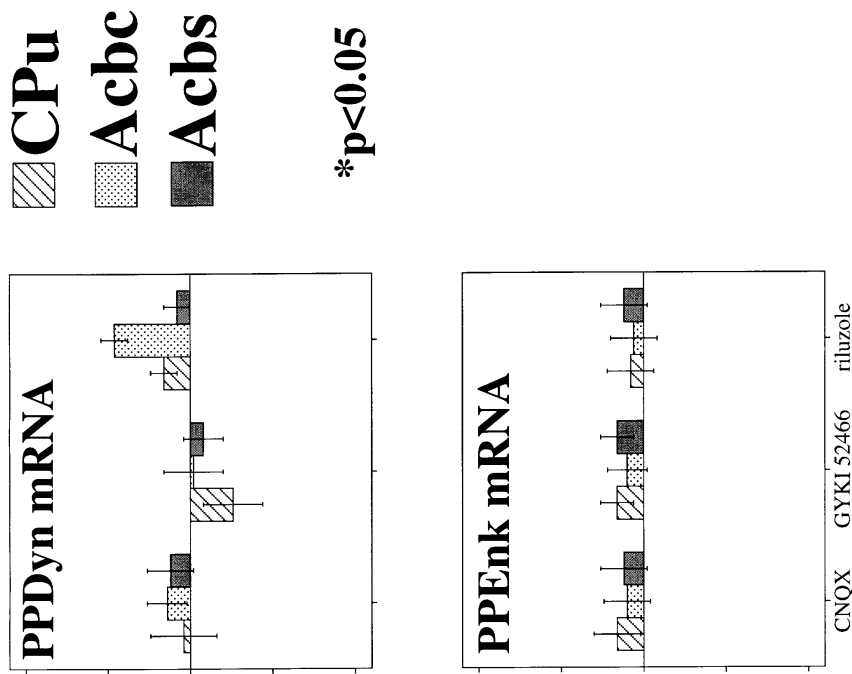

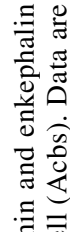
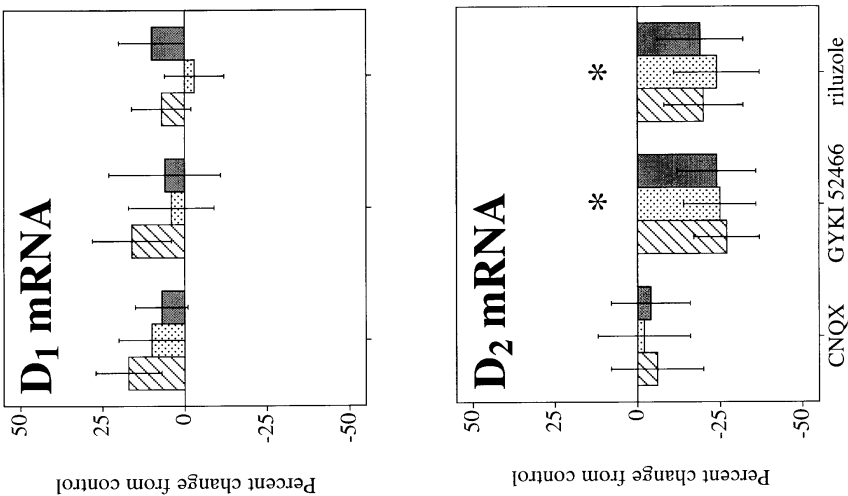

옹

-

च

o

원

政

跣

0 U 잉

$\ltimes$ 爻.

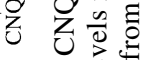

40

는 西

焉

ㄱㅇㅇㅇ

될

웍은

웡

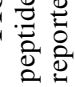


treatment do not represent a general property of ionotropic glutamate receptor blockade, but may be subtype specific.

$\mathrm{D}_{2}$ mRNA levels were decreased by GYKI52466 but not CNQX, indicating that the less selective AMPA and kainate receptor antagonist had a different effect than the more selective AMPA receptor antagonist. Perhaps the different synaptic localization of AMPA and kainate receptors is associated with this pattern. Kainate receptors are predominantly presynaptic autoreceptors, while AMPA receptors are predominantly postsynaptic. ${ }^{3}$ Modulation of autoreceptors and postsynaptic receptors by CNQX may affect overall glutamatergic activity differently than GYKI52466, which may not induce alterations in striatal dopamine receptor expression. However, riluzole would be expected to have similar effects to CNQX, if this is due to concomitant autoreceptor and postsynaptic effects. The change in presynaptic release of glutamate would be expected to affect activity of postsynaptic glutamate receptors, but riluzole had an effect similar to a relatively selective AMPA receptor antagonist. There appears to be a complicated pattern of regulation that requires further elucidation.

Opioid peptide precursor levels did not change, although we only measured mRNA levels. There are multiple levels of regulation for the expression of fully processed endogenous opioid peptides; it is possible that these drugs affected opioid peptide expression, but we could not detect it with in situ histochemistry. Likewise, this study does not address whether the mRNA levels of the $\mathrm{D}_{1}$ and $\mathrm{D}_{2}$ dopamine receptors reflect final receptor protein levels. These questions are important because the intrinsic striatal circuitry suggests that $\mathrm{D}_{2}$ receptor and enkephalin expression should both be affected. There are direct and indirect striatal efferent pathways that participate in the balance of striatal activity. ${ }^{4}$ The direct pathway is comprised of dopaminergic projections from SNc and VTA to the $\mathrm{CPu}$, core, and shell, and reciprocal striatal projections directly back to the substantia nigra, pars reticulata $(\mathrm{SNr})$ or VTA. ${ }^{4}$ The indirect pathway also serves as a feedback loop, but involves several other regions. $\mathrm{CPu}$ neurons project to the globus pallidus, which in turn sends GABAergic projections to the subthalamic nucleus. ${ }^{4}$ Glutamatergic neurons in this nucleus project back to the $\mathrm{SNr}$ directly, completing the loop. ${ }^{4}$ Core and shell neurons both project to the ventral pallidum, and then back to the $\mathrm{SNr}$ or VTA. Activation of the direct and indirect pathways appears to have opposite electrophysiological effects on midbrain dopaminergic neurons. ${ }^{4}$ Further, the striatal neurons in the direct and indirect pathways differ phenotypically from each other. $\mathrm{CPu}$ cells of the direct pathway express the $\mathrm{D}_{1}$ receptor and prodynorphin, while those that project to the pallidum express $\mathrm{D}_{2}$ receptors and proenkephalin-derived peptides..$^{5}$ The colocalization of dopamine receptor subtype and neuropeptide is more strongly associated with motor than limbic function, as this colocalization appears to break down in the shell. ${ }^{6}$ In addition, the identification of a striatal neuron as being part of the indirect or direct circuit based on $\mathrm{D}_{1}$ versus $\mathrm{D}_{2}$ expression also seems to breakdown in core and shell. ${ }^{7} \mathrm{D}_{1}$ receptors are expressed in both direct and indirect pathway neurons, though $\mathrm{D}_{2}$ expression is limited to the indirect pathway. ${ }^{7}$ Still, altered expression of these receptors may reflect a differential activation of these two pathways, providing a neurochemical anatomical basis to examine the direct and indirect pathways. Our findings of changes in $\mathrm{D}_{2}$ - but not $\mathrm{D}_{1}$-receptor ex- 
pression would be consistent with a preferential effect of AMPA receptor modulation of the indirect striatal efferent pathways.

\section{REFERENCES}

1. Carlsson, M. \& A. Carlsson. 1990. Schizophrenia: a subcortical neurotransmitter imbalance syndrome? Schizophr. Bull. 16: 425-432.

2. Healy, D.J. \& J.H. Meador-WoodrufF. 1996. Differential regulation, by MK-801, of dopamine receptor gene expression in rat nigrostriatal and mesocorticolimbic systems. Brain Res. 708: 38-44.

3. Wheal, H.V. \& A.M. Thomson. 1995. Excitatory Amino Acids and Synaptic Neurotransmission. Academic Press. London.

4. Kalivas, P.W. \& C.D. Barnes. 1993. Limbic Motor Circuits and Neuropsychiatry. CRC Press. Boca Raton, FL.

5. Gerfen, C.R. 1992. The neostriatal mosaic: multiple levels of compartmentalization. Trends Neurosci. 15: 133-139.

6. Curran, E.J. \& S.J. WatSON. 1995. Dopamine receptor mRNA expression patterns by opioid peptide cells in the nucleus accumbens of the rat: a double in situ hybridization study. J. Comp. Neurol. 361: 57-76.

7. Lu, X.Y., M.B. Ghasemzadeh \& P.W. Kalivas. 1998. Expression of $\mathrm{D}_{1}$ receptor, $\mathrm{D}_{2}$ receptor, substance $\mathrm{P}$, and enkephalin messenger RNAs in the neurons projecting from the nucleus accumbens. Neuroscience 82: 767-780. 